\title{
Basic Fibroblast Growth Factor and Local Injury Protect Photoreceptors from Light Damage in the Rat
}

\author{
Ella G. Faktorovich, ${ }^{1}$ Roy H. Steinberg, ${ }^{1,2,4}$ Douglas Yasumura, ${ }^{1,3}$ Michael T. Matthes, ${ }^{1}$ and Matthew M. \\ LaVail $1,3,4$ \\ Departments of ${ }^{1}$ Ophthalmology, ${ }^{2}$ Physiology, and ${ }^{3}$ Anatomy and ${ }^{4}$ Neuroscience Program, University of California, San \\ Francisco, California 94143-0730
}

Injection of basic fibroblast growth factor (bFGF) into the eye, intravitreally or subretinally, delays photoreceptor degeneration in inherited retinal dystrophy in the rat, as does local injury to the retina (Faktorovich et al., 1990). To determine whether this heparin-binding peptide or local injury is effective in any other form of photoreceptor degeneration, we examined their protective roles in light damage. Albino rats of the F344 strain were exposed to 1 or 2 weeks of constant fluorescent light (115-200 footcandles), either with or without $1 \mu \mathrm{l}$ of bFGF solution (1150 $\mathrm{ng} / \mu \mathrm{l}$ in PBS) injected intravitreally or subretinally $2 \mathrm{~d}$ before the start of light exposure. Uninjected and intravitreally PBS-injected controls showed the loss of a majority of photoreceptor nuclei and the loss of most inner and outer segments after 1 week of light exposure, while intravitreal injection of bFGF resulted in significant photoreceptor rescue. The outer nuclear layer in bFGF-injected eyes was two to three times thicker than in controls, and the inner and outer segments showed a much greater degree of integrity. Following recovery in cyclic light for $10 \mathrm{~d}$ after 1 week of constant light exposure, bFGFinjected eyes showed much greater regeneration of photoreceptor inner and outer segments than did the controls. bFGF also increased the incidence of presumptive macrophages, located predominantly in the inner retina, but the evidence suggests they are not directly involved in photoreceptor rescue.

Subretinal injection of bFGF resulted in photoreceptor rescue throughout most of the superior hemisphere in which the injection was made, with rescue extending into the inferior hemisphere in many of the eyes. Remarkably, the insertion of a dry needle or injection of PBS into the subretinal space also resulted in widespread photoreceptor rescue, extending through $70 \%$ or more of the superior hemisphere, and sometimes into the inferior hemisphere. This implicates the release and widespread diffusion of some endogenous survival-promoting factor from the site of injury in the retina.

Our findings indicate that the photoreceptor rescue activ-

Received Aug. 8, 1991; revised Apr. 9, 1992; accepted Apr. 14, 1992.

This work was supported by NIH Research Grants EY01919, EY06842, and EY01429, by CORE Grant EY02162, and by funds from the Retinitis Pigmentosa Foundation Fighting Blindness, Research to Prevent Blindness, and That Man

May See, Inc. We thank Dr. D. Gospodarowicz for the gift of bFGF, and Nancy Lawson and Gloria Riggs for technical and secretarial assistance.

Correspondence and reprint requests should be addressed to Matthew M. LaVail, Beckman Vision Center, UCSF School of Medicine, San Francisco, CA 94143 0730 .

Copyright (c) 1992 Society for Neuroscience $0270-6474 / 92 / 123554-14 \$ 05.00 / 0$ ity of bFGF is not restricted to inherited retinal dystrophy in the rat, and that light damage is an excellent model for studying the cellular site(s), kinetics, and molecular mechanisms of both the normal function of bFGF and its survival-promoting activity. Moreover, the injury-related rescue suggests that survival-promoting factors are readily available to provide a protective role in case of injury to the retina, presumably comparable to those that mediate the "conditioning lesion" effect in other neuronal systems.

A major goal of recent rescarch on retinal degencrations is to delay or prevent the loss of photoreceptor cells. In one form of retinal degeneration, inherited retinal dystrophy in the Royal College of Surgeons (RCS) rat, photoreceptor degeneration results secondarily from mutant gene expression in the cells of the retinal pigment epithelium (RPE) (Mullen and LaVail, 1976). In this mutant, photoreceptor degeneration recently has been prevented or delayed by three approaches. First, by experimentally transplanting wild-type RPE cells from normal rats into the retinas of mutant RCS rats at early stages of the disease, photoreceptors located adjacent to the transplanted RPE were "rescued" or prevented from degenerating (Li and Turner, 1988b; Lopez et al., 1989). Second, we have recently been able to delay photoreceptor degeneration significantly in RCS rats by the subretinal or intravitreal injection of the heparin-binding peptide basic fibroblast growth factor (bFGF) (Faktorovich et al., 1990). Third, photorcceptor degencration has becn delaycd in RCS rats in the region of subretinal injections of saline (Faktorovich et al., 1990; Silverman and Hughes, 1990; Blair et al., 1991) or subretinal insertion of a dry needle (Faktorovich et al., 1990), presumably due to cellular factors released by injury from the inserted needle (Faktorovich et al., 1990).

The rationale for exploring the effect of bFGF in retinal dystrophy arose from observations that (1) diffusible factors appeared to be involved in the rescue of photoreceptors located somewhat beyond the boundaries of normal RPE cells both in experimental chimeras (Mullen and LaVail, 1976) and in transplantation studies (Li and Turner, 1988b; Gouras et al., 1989), (2) bFGF is found in the retina (D'Amore and Klagsbrun, 1984; Baird et al., 1985a; Courty et al., 1985; Plouët et al., 1986, 1988; Mascarelli et al., 1987; Hanneken et al., 1989; Noji et al., 1990) and RPE (Schweigerer et al., 1987; Sternfeld et al., 1989), (3) bFGF receptors are present on rod outer segments (Plouët, 1988), (4) bFGF induces retinal regeneration from embryonic chick RPE cells (Park and Hollenberg, 1989), and (5) bFGF appears to act as a survival-promoting neurotrophic agent in the CNS and PNS in at least three respects: (1) it promotes neuronal 
survival in culture (Unsicker et al., 1987; Hatten et al., 1988; Grothe et al., 1989), (2) it prevents ontogenetic neuronal cell death (Dreyer et al., 1989), and (3) it reduces axotomy-induced neuronal cell death (Sievers et al., 1987; Anderson et al., 1988; Otto et al., 1989).

Is the rescue effect of bFGF specific to inherited retinal dystrophy in the RCS rat, or is the growth factor effective in delaying other forms of photoreceptor degcncration? Is the injury-induced rescue of photoreceptors also effective in other forms of retinal degeneration? To answer these questions, we have explored the protective roles of bFGF and needle-induced injury in a noninherited form of photoreceptor degeneration, damage produced by exposure of albino animals to constant light. An additional reason for examining the protective effect of bFGF in light damage was the need to obtain a more optimal model to explore the cellular site(s), kinetics, and molecular mechanisms of bFGF rescue in photoreceptors. The RCS rat requires experiments at a precise age in a strain that breeds only moderately well (LaVail et al., 1975; Hess et al., 1981), and in which the photoreceptor degeneration is relatively slow, requiring a 1-2 month survival period for experimental purposes (Faktorovich et al., 1990). In contrast, light damage in the albino rat can be studied within a broad age range in animals that breed well, and the period required for photoreceptor degeneration is only days to 1-2 weeks (Rapp and Williams, 1980; LaVail et al., 1987c). In this article, we show that both bFGF and needleinduced injury protect photoreceptors from the damaging effect of light.

Brief descriptions of some of the findings in the present study have been presented elsewhere (Faktorovich et al., 1991; LaVail et al., 1991; Steinberg et al., 1991).

\section{Materials and Methods}

F344 male albino rats were obtained at 2-5 months of age (Simonsen Laboratories, Inc., Gilroy, CA) and maintained in our cyclic light environment $[12 \mathrm{hr}$ on, $12 \mathrm{hr}$ off at an in-cage illuminance of less than 25 footcandles (ft-c)] for 9 or more days before being exposed to constant light. The rats werc cxposed to 1 or 2 weeks of constant light at an illuminance level of 115-200 ft-c (most rats received 125-170 ft-c) provided by two $40 \mathrm{~W}$ General Electric Cool White fluorescent bulbs with a white reflector that was suspended $60 \mathrm{~cm}$ above the floor of the cage. During light exposure, rats were maintained in transparent polycarbonate cages with stainless-steel wire bar covers. A water bottle was kept in the appropriate depression in the cage cover, but food was placed in the bottom of the cage on the bedding (light birch chip). All procedures involving the rats adhered to the ARVO Resolution on the Use of Animals in Research and the guidelines of the UCSF Committee on Animal Research.

Two days before constant light exposure, rats anesthetized with a ketamine-xylazine mixture were injected intravitreally with $1 \mu \mathrm{l}$ of affinity-purified, human recombinant bFGF (specific activity, $50-80 \mathrm{pg}$ / $\mathrm{ml}$ protein for $50 \%$ effective dosc in $3 \mathrm{~T} 3$ fibroblasts; gencrously provided by D. Gospodarowicz, UCSF) dissolved in phosphate-buffered saline (PBS) at a concentration of $1150 \mathrm{ng} / \mu \mathrm{l}$. The injections were made with the insertion of a 32 gauge needle through the sclera, choroid, and retina approximately midway between the ora serrata and equator of the eye. The bFGF-injected animals were compared to either uninjected littermates or those that received intravitreal injections of $1 \mu \mathrm{l}$ of PBS alone, as well as animals that were not exposed to constant light. In some cases, $1 \mu \mathrm{l}$ of bFGF solution was injected subretinally with a transcleral approach as described elsewhere (Li and Turner, 1988a). Controls for the subretinal bFGF injections included the injection of $1 \mu \mathrm{l}$ of PBS alone, or the insertion of a dry needle with no injection. Dry needle insertion also provided the eyes with which to study injury-related rescue. In all cases, the injections were made into the superior hemisphere of the eye.

Immediately following constant light exposure, or after a recovery period in cyclic light for $10 \mathrm{~d}$, the rats were killed by overdose of carbon dioxide followed immediately by vascular perfusion of mixed aldehydes (LaVail and Battelle, 1975). The eyes were embedded in epoxy resin for sectioning at $1 \mu \mathrm{m}$ thickness to provide sections of the entire retina along the vertical meridian of the eye as previously described (LaVail and Battelle, 1975).

The degree of light- or injury-induced retinal degeneration was quantified by measuring outer nuclear layer (ONL) thickness, which is used as an index of photoreceptor cell loss (LaVail et al., 1987a-c; Michon et al., 1991). A mean ONL thickness was obtained from a single section of each animal with the aid of a Bioquant morphometry system ( $R$ and $M$ Biometrics, Nashville, TN). In each of the superior and inferior hemispheres, ONL thickness was measured in nine sets of three measurements each (total of 27 measurements in each hemisphere). Each set was centered on adjacent $440 \mu \mathrm{m}$ lengths of retina (the diameter of the microscope field at $400 \times$ magnification). The first set of measurements was taken at approximately $440 \mu \mathrm{m}$ from the optic nerve head, and subsequent sets were located more peripherally. Within each 440 $\mu \mathrm{m}$ length of retina, the three measurements were made at defined points separated from one another by $75 \mu \mathrm{m}$ using an eyepiece micrometer. In this way, the 54 measurements in the two hemispheres sampled representative regions of almost the entire retinal section. As a consequence, mean ONL thickness was proportionally equivalent (within $0.5 \%$ ) to the value obtained by integration of the ONL thickness over the entire retinal section as recommended by Williams and Howell (1983).

In addition to mean ONL thickness for the entire retinal section, we have compared, among different groups of rats, ONL thickness of the region of retina most sensitive to the damaging effects of light, the posterior to equatorial retina along the vertical meridian in the superior hemisphere of the eye (Noell, 1979; Rapp and Williams, 1980). The thinnest ONL measurements in the present study were among the nine measurements taken in the second through fourth $440 \mu \mathrm{m}$ fields in the superior hemisphere, as expected from the work of Rapp and Williams (1980) and our previous light-damage studies on F344 rats (LaVail et al., 1987c). We used the mean of the smallest three consecutive values (regardless of whether they were in the same $440 \mu \mathrm{m}$ field) for the ONL measurement of the most sensitive region.

In each of the experiments where ONL thickness was quantified, a single section from the retinas of at least 16 (usually 20 or more) eyes was measured, except where rats had subretinal injections or had a 10 $\mathrm{d}$ recovery period in cyclic light, in which case at least six, and usually eight, eyes were examined. Statistical comparisons between treated and untreated groups were made using the Student's $t$ test.

Since the number of presumptive macrophages had been seen to increase following bFGF injection in RCS rats (Faktorovich et al., 1990), the number of these cells was counted in complete sections in the inner retina (inner nuclear layer to the inner limiting membrane) and in the photoreceptor layer (between the outer limiting membrane and the apical surface of the RPE). The tabulation of macrophages was further subdivided into superior and inferior retinal hemispheres to correlate with different degrees of photoreceptor rescue in the different hemispheres in some experiments. Identification of the cells was based primarily on the densely staining cytoplasm and the characteristic sharply demarcated, peripheral rim of nuclear heterochromatin, as described previously (Essner and Gorrin, 1979; LaVail, 1979; Sanyal et al., 1984).

\section{Results}

Photoreceptor damage after 1 or 2 weeks of constant light in uninjected rats

Degeneration of photoreceptor cells after 1 or 2 weeks of constant light was as expected from previous studies (Noell et al., 1966; O'Steen et al., 1972; Noell, 1979; LaVail, 1980; Rapp and Williams, 1980; LaVail et al., 1987c). Briefly, after 1 week of constant light, degeneration was most severe in the posterior to equatorial region of the superior hemisphere, where the ONL was reduced from the normal 8-10 rows (Fig. $1 A$ ) to 1-3 rows (Fig. $1 B$ ) of photoreceptor nuclei. In this most degenerated region, only a very few fragments of photoreceptor inner and outer segments remained (Fig. $1 B$ ). With increasing distance from the most degenerated region, either into the peripheral superior hemisphere or into the inferior hemisphere, fewer photoreceptors were lost, the ONL was correspondingly thicker (Fig. 3), 

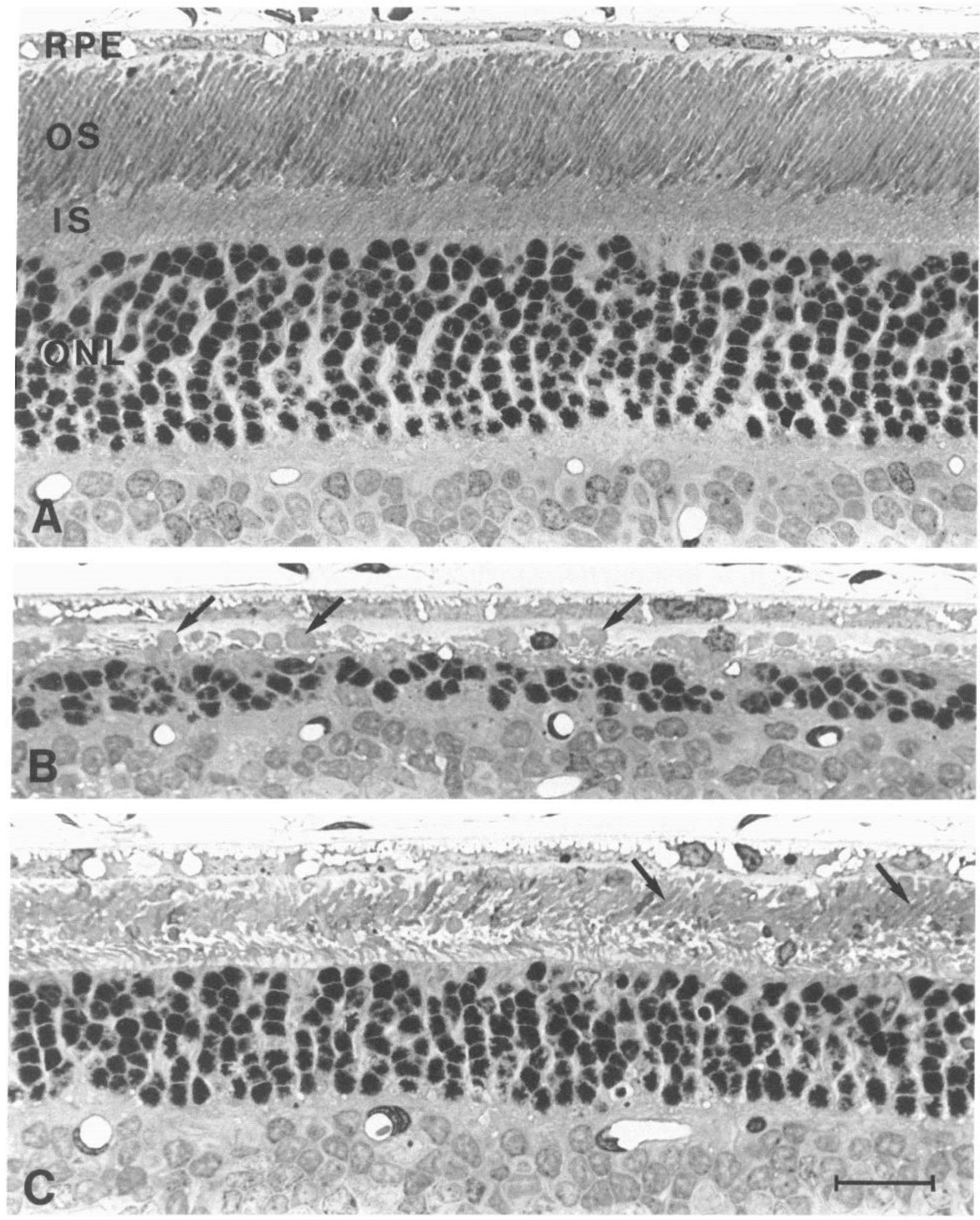

Figure 1. Light micrographs of retinas from F344 albino rats taken from the posterior superior region of the eye that is most sensitive to the damaging effects of constant light. $A$, Normal retina from an uninjected rat kept in cyclic light. $B$, Retina from an uninjected rat exposed to constant light for 1 week. The ONL has been reduced to one to three rows of photoreceptor nuclei, no photoreceptor inner segments are present, and the remaining outer segments are in the form of large rounded or oblong profiles (arrows) that are as large as photoreceptor nuclei. $C$, Retina from a rat injected intravitreally with bFGF $2 \mathrm{~d}$ before a 1 week exposure to constant light. The ONL shows six or seven rows of nuclei, some inner segments are present, albeit shorter than normal (compare to $A$ ), and photoreceptor outer segments are present. Although most of the outer segments are somewhat disorganized, they are mostly of normal diameter (arrows). $I S$, inner segments; $O S$, outer segments. Toluidine blue stain. Scale bar, $20 \mu \mathrm{m}$. 


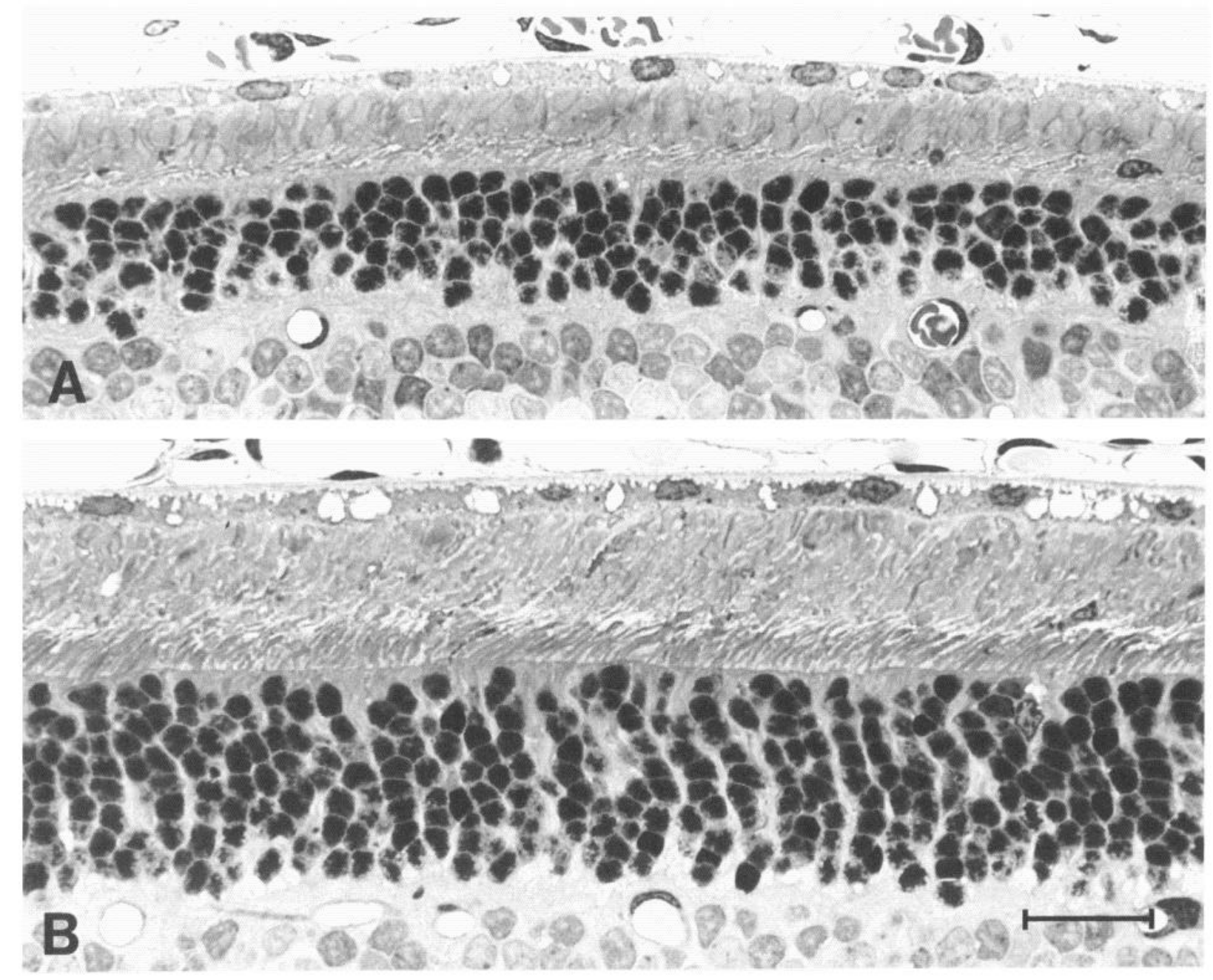

Figure 2. Light micrographs illustrating the peripheral retinas of rats exposed to constant light for 1 week. $A$, Uninjected eye. The ONL shows a greater number of surviving photoreceptor nuclei than the posterior retina (Fig. 1B), some very short inner segments are present, and the outer segment membranes are arranged in large rounded profiles or large membranous whorls. $B$, Peripheral retina from a rat injected intravitreally with bFGF $2 \mathrm{~d}$ before the start of light exposure. The ONL is thicker and the inner and outer segments are longer and more normally aligned than in the more degenerated central retina (Fig. 1C). Toluidine blue stain. Scale bar, $20 \mu \mathrm{m}$.

and the inner and outer segments were relatively less damaged (Fig. 2A). Inner segments were observed in the peripheral retina, but they were never of normal length (compare Figs. 1A, 2A).

With increasing distance from the most degenerated zone, outer segments showed a relatively discrete gradient of degenerative changes. In the most degenerated zone, small fragments of outer segments were intermixed with a relatively small number of large, rounded or oblong profiles (Fig. 1B). These profiles were identified by electron microscopy in previous light damage studies as degenerating outer segments, which were transformed into large, sac-like structures filled with elongated, tubular membranes (Kuwabara and Gorn, 1968; Grignolo et al., 1969). The rounded profiles were usually as large in diameter as rod cell nuclei $(4-5 \mu \mathrm{m})$ (Fig. $1 B)$, significantly larger than the $1.5 \mu \mathrm{m}$ diameter of normal rod outer segments in the rat (Battelle and LaVail, 1978). Somewhat distant from the most degenerated zone, the outer segment region consisted entirely of large, rounded membranous profiles (Fig. $2 A$ ). In the most peripheral retina, where the least photoreceptor cell loss occurred (Fig. 3), large rounded profiles were still present, but some elongated outer segments were occasionally observed (not shown). Most of these, however, were much larger in diameter and less uniform in caliber and orientation than normal outer segments. Only rarely were any outer segments of normal diameter present in the retinas after 1 week of light exposure, and these were found in the extreme peripheral retina.

Two weeks of constant light produced a more severe degeneration than 1 week of light. There was a greater loss of photoreceptor nuclei throughout the retina (Fig. 4), and a much greater expanse of the retina appeared similar to the most degenerated regions seen after 1 week of constant light.

When PBS was injected intravitreally, animals kept in cyclic light showed retinas that were indistinguishable from those of uninjected rats. Those rats that were injected intravitreally with PBS and subjected to constant light for 1 or 2 weeks showed retinas that were quantitatively indistinguishable from those of uninjected light-damaged rats. Although the ONL thickness measurements were slightly greater in PBS-injected rats than in uninjected animals in some individual experiments, they were not significantly different statistically. Therefore, the data for 

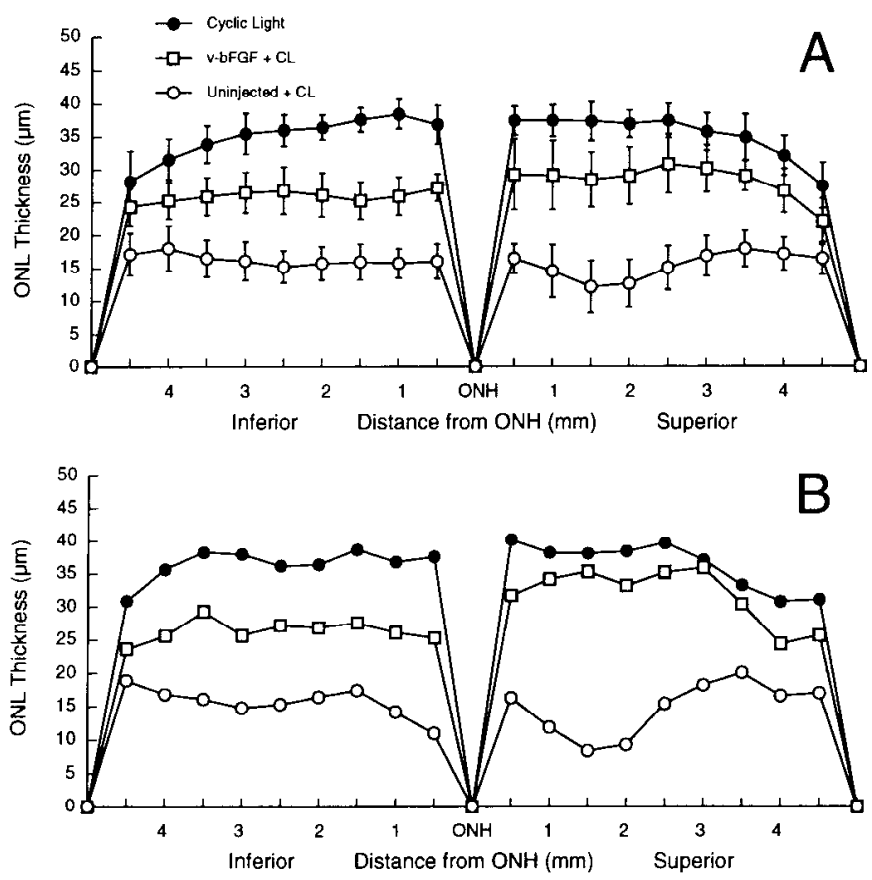

Figure 3. Measurements of ONL thickness along the vertical meridian of the eye in albino F344 rats either maintained in cyclic light or after 1 week of constant light, either with an intravitreal injection of bFGF $2 \mathrm{~d}$ before the start of light exposure $(v-b F G F+C L)$ or without injection (Uninjected $+C L$ ). $A$, Each data series shows the mean $\pm \mathrm{SD}$ of all experiments $(C L, n=12 ; v-b F G F+C L, n=14 ;$ Uninjected $+C L, n$ $=12$ ). $B$, Each data series shows measurements of a single section from selected animals chosen to illustrate the most severe loss of photoreceptor nuclei typically seen in the posterior to equatorial superior hemisphere in the Uninjected $+C L$ group, as well as the greater degree of rescue in the superior hemisphere than in the inferior hemisphere often seen in the $v-b F G F$ group. In this case, the ONL of the superior retina is almost of normal thickness. $O N H$, optic nerve head.

the rats injected intravitreally with PBS are not presented, and references to uninjected controls in subsequent experiments refer to PBS-injected controls as well.

The reason for the slightly greater (but insignificant) overall mean ONL thickness in the PBS-injected eyes was the presence of a small region of retina that showed a thicker ONL surrounding the injection site in the equatorial to far peripheral retina in the superior hemisphere. The extent of this apparent injuryrelated photoreceptor rescue was variable, but usually limited to a diameter of about $100-800 \mu \mathrm{m}$, centered on the injury caused by the needle that traversed the retina. This localized thickening of the ONL was small enough that in many eyes in which the $1 \mu \mathrm{m}$ plastic section did not include the needle site, no thickening of the ONL was seen.

A small number of cyes injected intravitreally with PBS (or bFGF) had conspicuous bleeding into the vitreous. These eyes usually showed an irregular but maximal photoreceptor rescue, sometimes with photoreceptor rosettes in the ONL, as seen previously in RCS rats (Faktorovich et al., 1990). Such animals were excluded from the data analysis.

\section{Photoreceptor rescue following intravitreal bFGF injection}

Photoreceptors of bFGF-injected eyes of rats maintained in cyclic light for 1 or 2 weeks appeared indistinguishable from uninjected or PBS-injected controls maintained in cyclic light. When rats were exposed to constant light for 1 week beginning
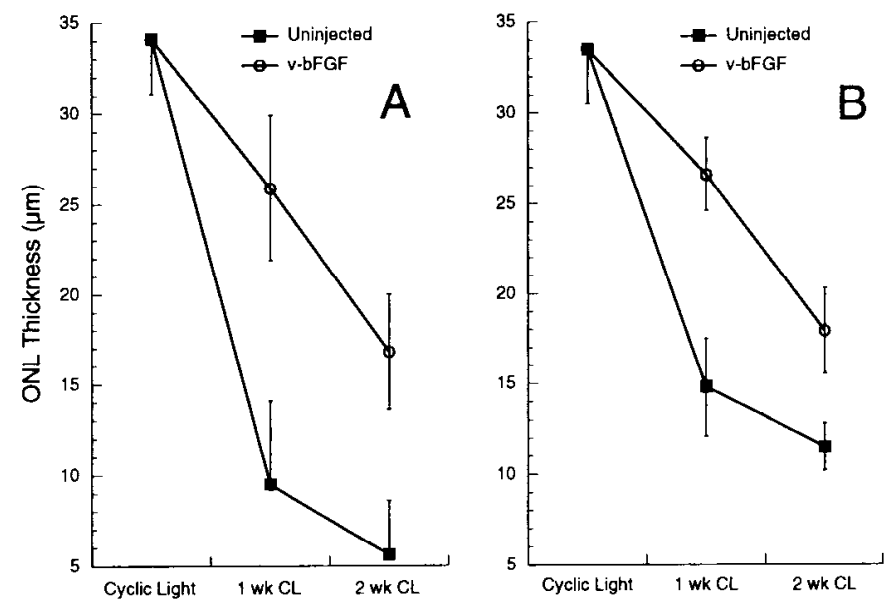

Figure 4. Mean ONL thickness of the retinas of albino F344 rats, either maintained in cyclic light or exposed to constant light $(C L)$ for 1 or 2 weeks, and that were either uninjected controls or injected intravitreally with $\mathrm{bFGF} 2 \mathrm{~d}$ before the start of light exposure $(v-b F G F)$. Data points are the mean $( \pm \mathrm{SD})$ of 16 or more eyes. $A$, Measurements taken from the most degenerated region of the eye in the superior hemisphere (see Materials and Methods). $B$, Measurements taken of the entire retina (see Materials and Methods). In all cases, the ONL of bFGF-treated retinas was thicker than that of uninjected rats at a high level of statistical significance ( $P=0.0002$ or less).

$2 \mathrm{~d}$ after intravitreal bFGF injection, photoreceptor degeneration was far less extensive than in uninjected eyes exposed to the same period of constant light (compare Fig. $1 B, C$ ). Far fewer photoreceptor nuclei degenerated, so in all regions of the eye the ONL was thicker than in corresponding regions of retinas in uninjected eyes (Fig. 3). Indeed, after 1 week of constant light, the ONL in the most sensitive region in the superior hemisphere was almost three times thicker than that of uninjected eyes (Fig. $4 A$ ), and it was almost two times thicker in ONL mcasurements of the entire retina (Fig. $4 B$ ). Photoreceptor rescue by bFGF injection was consistently greater in the superior than in the inferior hemisphere, with the greatest relative rescue occurring in the region of retina most sensitive to the damaging effects of light (Fig. 3).

It should be noted that the somewhat greater variance in ONL measurements in the most sensitive region (Fig. $4 A$ ) compared with the entire retina (Fig. $4 B$ ) was probably due to the sections not passing through the exact center of the most sensitive (i.e., most degenerated) region in every case. This is consistent with the observation of a relatively wide range of minimal ONL thicknesses, 2.7-16.2 $\mu \mathrm{m}$ (mean of three smallest consecutive measurements in a given eye).

With intravitreal bFGF injection there was a marked reduction in the degenerative changes of light damage in photoreceptor inner and outer scgments. After 1 weck of constant light, discrete inner segments were present even in the most sensitive region of the retina, as were some outer segments of normal diameter (Fig. 1C). Distant from this region, inner and outer segments appeared even less damaged (Fig. $2 B$ ). Large, rounded, sac-like profiles in the outer segment zone, as seen in the control (uninjected) light-damaged rats, were almost never found in the bFGF-treated rats after 1 week of constant light.

After 2 weeks of constant light, retinas of bFGF-injected eyes were more degenerated than those in $\mathrm{bFGF-injected} \mathrm{eyes} \mathrm{after}$ 1 week of light exposure, but were still significantly less degenerated than those in uninjected eyes (Fig. 4). After 2 weeks of 
light exposure, large rounded profiles were present in the outer segment zone when the ONL consisted of four or fewer rows of nuclei, but they were infrequent when more than four rows of nuclei were present.

\section{Recovery of photoreceptors in cyclic light following light damage}

Since rod outer segments can regencratc following sublethal light damage to photoreceptors (Kuwabara, 1970; Lanum, 1978; McKechnie and Foulds, 1980; Wyse, 1980), we examined retinas of rats that were allowed to recover for $10 \mathrm{~d}$ in cyclic light following either 1 or 2 weeks of constant light, either with or without intravitreal bFGF injection. The $10 \mathrm{~d}$ period was chosen because it is the approximate duration of one rod outer segment renewal cycle in the rat (Young, 1967; LaVail et al., 1972; LaVail, 1981a).

After $10 \mathrm{~d}$ of recovery, ONL thicknesses in uninjected rats had not changed significantly from those at the end of 1 or 2 weeks of constant light exposure (Fig. 5). Thus, removal of rats from constant light appeared to halt the loss of photoreceptor cell nuclei. In bFGF-treated eyes, ONL measurements after the $10 \mathrm{~d}$ recovery were slightly less than before the recovery, but the ONL thickness appeared to stabilize at this level, based on preliminary observations with longer recovery periods (E. G. Faktorovich, R. H. Steinberg, D. Yasumura, M. T. Matthes, and M. M. LaVail, unpublished observations).

After $10 \mathrm{~d}$ of recovery, photoreceptor inner and outer segments in uninjected rats did not appear to regenerate in the most degenerated region of the eye. In most other parts of the retina, however, there were clear signs of photoreceptor recovery. In most regions, inner segments had lengthened, and there were significantly more outer segment fragments of normal diameter than in eyes with no recovery period. In the more peripheral retina, where damage was less severe, large, rounded membranous profiles were still present in the outer segment zone, but many outer segments of normal diameter were also found, particularly in the inner part of the outer segment layer (Fig. 6A). These were shorter and less well aligned than normal, but they definitely showed at least a small degree of regeneration.

The bFGF-treatcd cycs, however, showed significantly greater regeneration of inner and outer segments in the $10 \mathrm{~d}$ recovery period than did the uninjected eyes. Although usually somewhat more disorganized than normal, inner and outer segments appeared almost normal in structure in the regions of best regeneration (Fig. 6B).

Overall, the degree of photoreceptor recovery in both bFGF treated and uninjected eyes appeared to be inversely proportional to the degree of light damage in two respects. In individual sections, recovery was greatest where photoreceptor degeneration was least. In addition, individual rats differed somewhat in the degree of photoreceptor cell loss, which is typical for lightdamage studies (Birch and Jacobs, 1977; LaVail, 1980), and the more severely light-damaged retinas had fewer outer segments of normal diameter after the recovery period than did the less severely damaged retinas.

\section{Photoreceptor rescue following subretinal bFGF injections}

Eyes subretinally injected with bFGF 2 d before a 1 week light exposure all showed extensive photoreceptor rescue in the superior hemisphere of the eye where the injection had been made (Fig. 7). The rescue effect was obvious throughout most of the superior hemisphere, and in four of six eyes the rescue effect

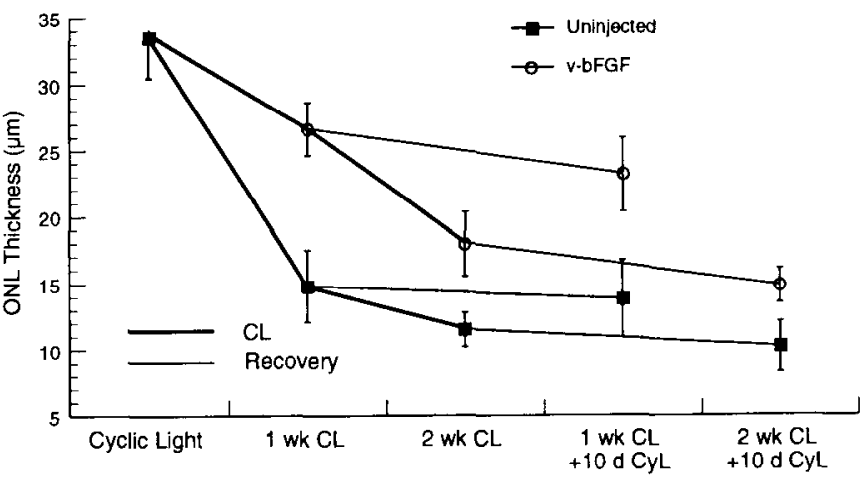

Figure 5. Mean ONL thickness of the entire retinas of albino F344 rats (see Materials and Methods) exposed to constant light $(C L)$ for 1 or 2 weeks, after which they were allowed to recover in cyclic light $(C y L)$ for $10 \mathrm{~d}$. Rats were either uninjected controls or were injected intravitreally with bFGF $2 \mathrm{~d}$ before the start of light exposure $(v-h F G F)$. The thick lines represent data from rats subjected to constant light, either with or without bFGF injection, whereas the thin lines extend from the time the rats were taken from the constant light to the data point obtained after $10 \mathrm{~d}$ of recovery in cyclic light. In all cases, the mean ONL thickness after $10 \mathrm{~d}$ in cyclic light was statistically indistinguishable ( $P$ $>0.05$ ) from the ONL thickness before the $10 \mathrm{~d}$ recovery period, except for the bFGF-treated retinas after 2 weeks of constant light $(P=0.0005)$. However, comparisons of the most degenerated region in the superior hemisphere showed no significant difference in this $(P=0.71)$ or any group of retinas $(P>0.05)$. Thus, little or no loss of photoreceptor cell nuclei occurs during the $10 \mathrm{~d}$ period of recovery in cyclic light in any of the groups. Each data point in the recovery experiments represents the mean $( \pm S D)$ of six or more eyes.

continued into the inferior hemisphere, in some cases extending to the equator of the inferior hemisphere (Fig. $7 B$ ). In all experiments, the integrity of the photoreceptor inner and outer segments was proportional to the degree of light damage (based on ONL thickness). Thus, in those regions of the inferior hemisphere where little or no rescue occurred, the retinas had an appearance similar to the uninjected rats exposed to 1 week of light.

\section{Photoreceptor rescue following subretinal dry needle or PBS}

Remarkably, insertion of a dry needle or injection of PBS into the subretinal space (five eyes each) produced a rescue qualitatively similar to that just described above for subretinal bFGF. The only apparent difference in the rescue effect was its slightly greater extent in the bFGF-injected eyes. The eyes that received the dry needle insertion or PBS injection into the subretinal space showed obvious photoreceptor rescue throughout $70 \%$ or more of the superior hemisphere, and one of the eyes with the needle insertion showed rescue that extended into the inferior hemisphere (Fig. $7 B$ ).

Figure 8 shows the site of needle injection (Fig. $8 A$ ) and an adjacent area (Fig. $8 B$ ) in the superior hemisphere in one experiment where a needle had been placed into the subretinal space (and ONL) of the superior hemisphere $2 \mathrm{~d}$ before a 1 week light exposure. Photoreceptor inner segments were almost of normal length, and outer segments, albeit somewhat disorganized, were abundant and mostly of normal diameter. Figure $8 \mathrm{C}$ shows the inferior hemisphere of the same retinal section shown in Figure 8, $A$ and $B$. Few, if any, normal outer segments were found here, and these consisted mostly of large membranous packets

We also studied the effect of a $10 \mathrm{~d}$ recovery period in cyclic light in dry needle experiments (six additional eyes). Inner and 


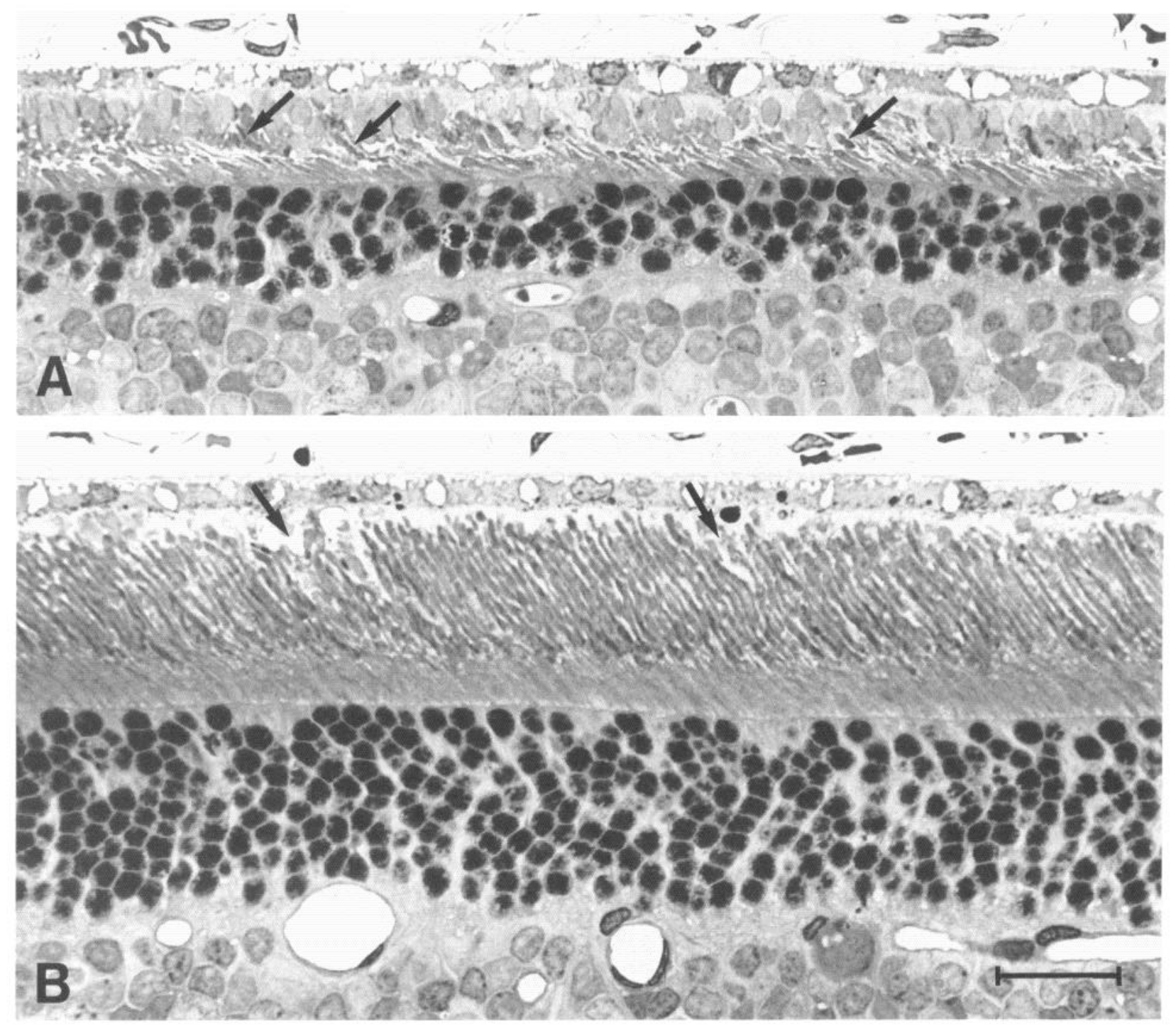

Figure 6. Light micrographs of retinas from rats exposed to constant light for 1 week followed by a $10 \mathrm{~d}$ recovery period in cyclic light. In each case, the region of the eye showing the greatest degree of recovery of inner and outer segments is illustrated. $A$, Retina from an uninjected eye shows longer inner segments than immediately after light exposure (compare Fig. $2 A$ ) and short, but distinct, fragments of outer segments (arrows) that have been generated during the $10 \mathrm{~d}$ recovery period. These underlie larger membranous whorls and large rounded profiles that were present immediately after light damage (Figs. $1 B, 2 A$ ). $B$, Retina from an eye injected intravitreally $2 \mathrm{~d}$ before the onset of constant light exposure. Some focal disruptions in outer segment alignment are present (arrows), but otherwise the retina appears almost normal. Toluidine blue stain. Scale bar, $20 \mu \mathrm{m}$.

outer segments in the superior hemisphere (region of needle insertion) showed a high degree of recovery that was indistinguishable from the recovery experiments in bFGF-injected eyes described above (data not shown). The more severely damaged inferior hemisphere showed only minimal inner and outer segment regeneration, like that of the recovery experiments in uninjected (or PBS-injected) eyes described above (data not shown). In the intervening areas of retina, there was a gradient of inner and outer segment regeneration that was approximately proportional to the degree of photoreceptor rescue.

\section{Increase in macrophage incidence}

Cells identified presumptively as macrophages are normally present in rodent retinas in the inner retina, predominantly in the inner plexiform layer (IPL) (Fig. 9A), and some are found, as well, in the outer plexiform layer (Sanyal, 1972) and outer segment zone (Sanyal et al., 1984). Intravitreal bFGF increased the incidence of macrophages (Fig. $9 B$ ), even in control rats maintained in cyclic light for $9 \mathrm{~d}$ after injection (Fig. 10A). This increase was greater in the superior than in the inferior retinal hemisphere (Fig. 10A), probably due to the greater concentration of bFGF near the injection site. Subretinal injections of bFGF in the superior hemisphere also caused an increase in macrophage numbers in the superior hemisphere (Fig. 10A). With both vitreal and subretinal bFGF, most of the macrophages were located in the IPL (Fig. 10B).

As expected from previous studies (O'Steen and Lytle, 1971; O'Steen and Karcioglu, 1974), 1 week of constant light, by itself, increased the incidence of macrophages. In contrast to the bFGF injections, macrophage numbers with constant light alone were uniformly greater in both hemispheres of the eye, and macrophages were present in both the IPL and outer segment zone 
(Fig. 10A,B). In most cases, the presumptive macrophages in the IPL were usually devoid of obvious inclusions (Fig. 9B), whereas most located in the outer segment zone contained many inclusions of cellular and outer segment debris.

Strikingly, the effects of vitreal bFGF and light exposure were additive for macrophage numbers in the IPL of both hemispheres. Thus, the light-exposed rats that had received vitreal bFGF showed a doubling in macrophage numbers over the uninjected light-exposed animals (Fig. 10A). It is interesting that the additive effect of light exposure and $b F G F$ persisted during the $10 \mathrm{~d}$ recovery period, while the effect of light exposure, by itself, showed a falloff during this period (Fig. 10A,B).

It is important to note that subretinal PBS and dry needle insertion did not increase the incidence of macrophages either in the cyclic light or constant light experiments (Fig. 10A). Thus, the extensive photoreceptor rescue observed with these procedures (Figs. 7,8 ) appeared unrelated to macrophage incidence

\section{Discussion}

Photoreceptor rescue by $b F G F$

Intravitreal and subretinal injections of bFGF prior to constant light exposure greatly ameliorated the damaging effects of light. Thus, the survival-promoting action of this heparin-binding peptide on photoreceptor degenerations is not specific to the RCS rat. The term "rescue" is often used casually to indicate the prevention of cell death. In the RCS rat with inherited retinal dystrophy, bFGF did not reverse the genetic defect and only delayed the loss of photoreceptor cells (Faktorovich et al., 1990), therefore resulting in a transient "rescue." In the case of constant light damage, bFGF results in a true rescue. With bFGF pretreatment, those photoreceptors that survived the light exposure continued to survive after the rats were removed from the constant light. Indeed, during the $10 \mathrm{~d}$ recovery period in cyclic light, surviving photoreceptors actually regenerated their inner and outer segments to a much greater extent and reestablished a much more normal anatomical relationship with the RPE compared to photoreceptors of the more severely damaged retinas that did not receive bFGF.

Photoreceptor outer segments in bFGF-treated and uninjected controls appeared qualitatively different after I week of constant light. In the uninjected (or PBS-injected) light-damaged controls, almost all outer segment membranes were in the form of large, rounded profiles, shown previously in light-damaged rat retinas to be large, sac-like structures filled with membranous profiles derived from degenerating outer segments (Kuwabara and Gorn, 1968; Grignolo et al., 1969). Such profiles rarcly were found in bFGF-treated retinas after 1 week of light damage, although many were seen in more severely degenerated retinas after 2 weeks of light exposure. The action spectrum of light damage in rats matches that of rhodopsin (Noell et al., 1966; Kaitz and Auerbach, 1980; Williams and Howell, 1983), and it has generally been found that photoreceptor outer segments sustain the initial insult (Kuwabara and Gorn, 1968; Grignolo et al., 1969; Shear et al., 1973). It has been reported that the degenerative transformation of rod outer segments to large, membranous profiles occurs within hours to several days after the onset of excessive light exposure (Kuwabara and Gorn, 1968; Grignolo et al., 1969). Thus, the absence of the large profiles after 1 week of light exposure in the bFGF-treated eyes was surprising. It appears that the rescue activity of bFGF occurs early enough in the degenerative process to retard the formation
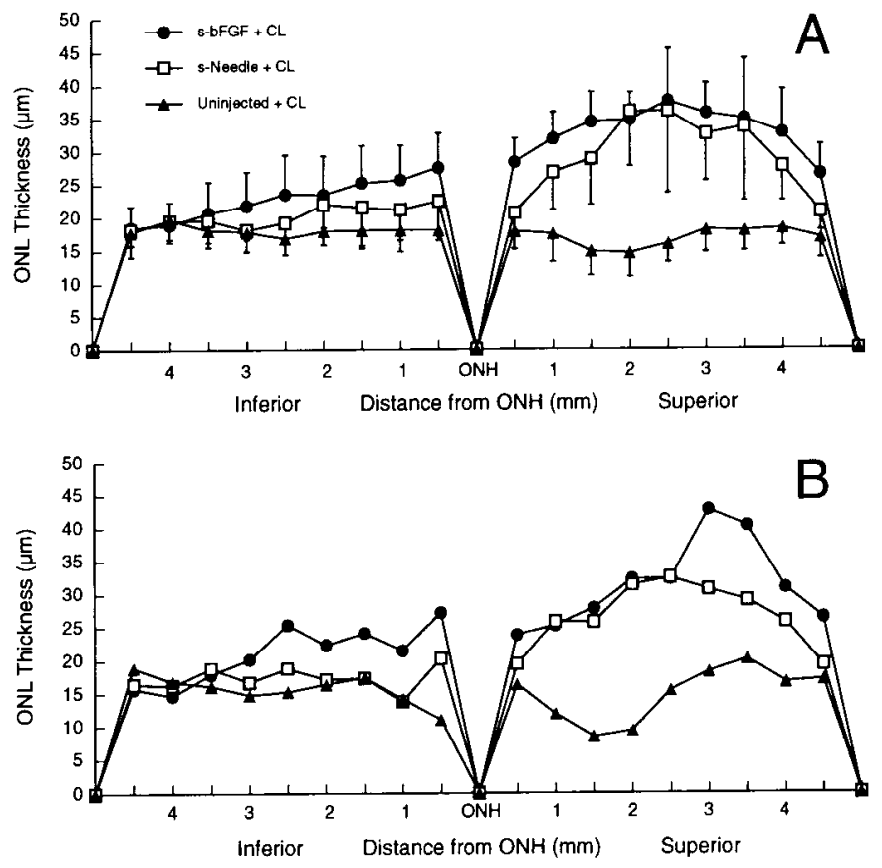

Figure 7. Measurements of ONL thickness along the vertical meridian of the eye in albino F344 rats exposed to 1 week of constant light, treated with one of the following: a subretinal injection of bFGF in the superior hemisphere $2 \mathrm{~d}$ before the start of light exposure $(s-b F G F+C L)$, the insertion of a dry needle into the subretinal space in the superior hemisphere $2 \mathrm{~d}$ before the start of light exposure $(s$-Needle $+C L)$, or no injection (Uninjected $+C L$ ). $A$, Each data series shows the mean $\pm \mathrm{SD}$ of all experiments $(s-b F G F+C L, n=6 ; s$-Needle $+C L, n=5 ; U n$ injected $+C L, n=6$ ). The $s$-Needle $+C L$ values are statistically indistinguishable $(P>0.05)$ from those of the uninjected rats at $0.5 \mathrm{~mm}$ in the superior hemisphere and at all points in the inferior hemisphere. The $s-b F G F+C L$ values are greater than those of the uninjected rats $(P<0.05)$ at 0.5 and $1.0 \mathrm{~mm}$ in the superior hemisphere, but do not differ statistically from any of the more peripheral values. Thus, on avcrage, the rescuc produced by subretinal needle insertion extended throughout most of the superior hemisphere, whereas the rescue produced by subretinal bFGF injection extended farther, to about $1 \mathrm{~mm}$ into the inferior hemisphere. $B$, Each data series shows measurements of a single section from selected animals chosen to illustrate the farthest extent into the inferior hemisphere of rescue produced by subretinal needle insertion and subretinal bFGF injection, compared to uninjected rats. $O N H$, optic nerve head.

of such large profiles. While it is tempting to infer that bFGF may, in some way, protect rod outer segments specifically, this cannot be distinguished at present from a survival-promoting effect on the cell as a whole. Thus, the survival-promoting action of bFGF may modify the susceptibility of the photoreceptor cell, as a whole, to the damaging effects of light, or it possibly could alter the usual sequence of cytopathological changes in light damage. The cellular mechanism(s) by which bFGF rescues photoreceptors from the damaging effects of light obviously remains to be shown, as it does for all other neuronal systems in which the peptide shows a survival-promoting action (Sievers et al., 1987; Unsicker et al., 1987; Anderson et al., 1988; Hatten et al., 1988; Dreyer et al., 1989; Grothe et al., 1989; Otto et al., 1989). Indeed, it is not even clear whether bFGF acts directly on neurons or indirectly through glial cells, or both (Hatten et al., 1988; Walicke and Baird, 1988; Engele and Bohn, 1991; Yoshida and Gage, 1991).

Light-induced photoreceptor cell death is thought to involve photoxidative processes that are initiated in the outer segment 


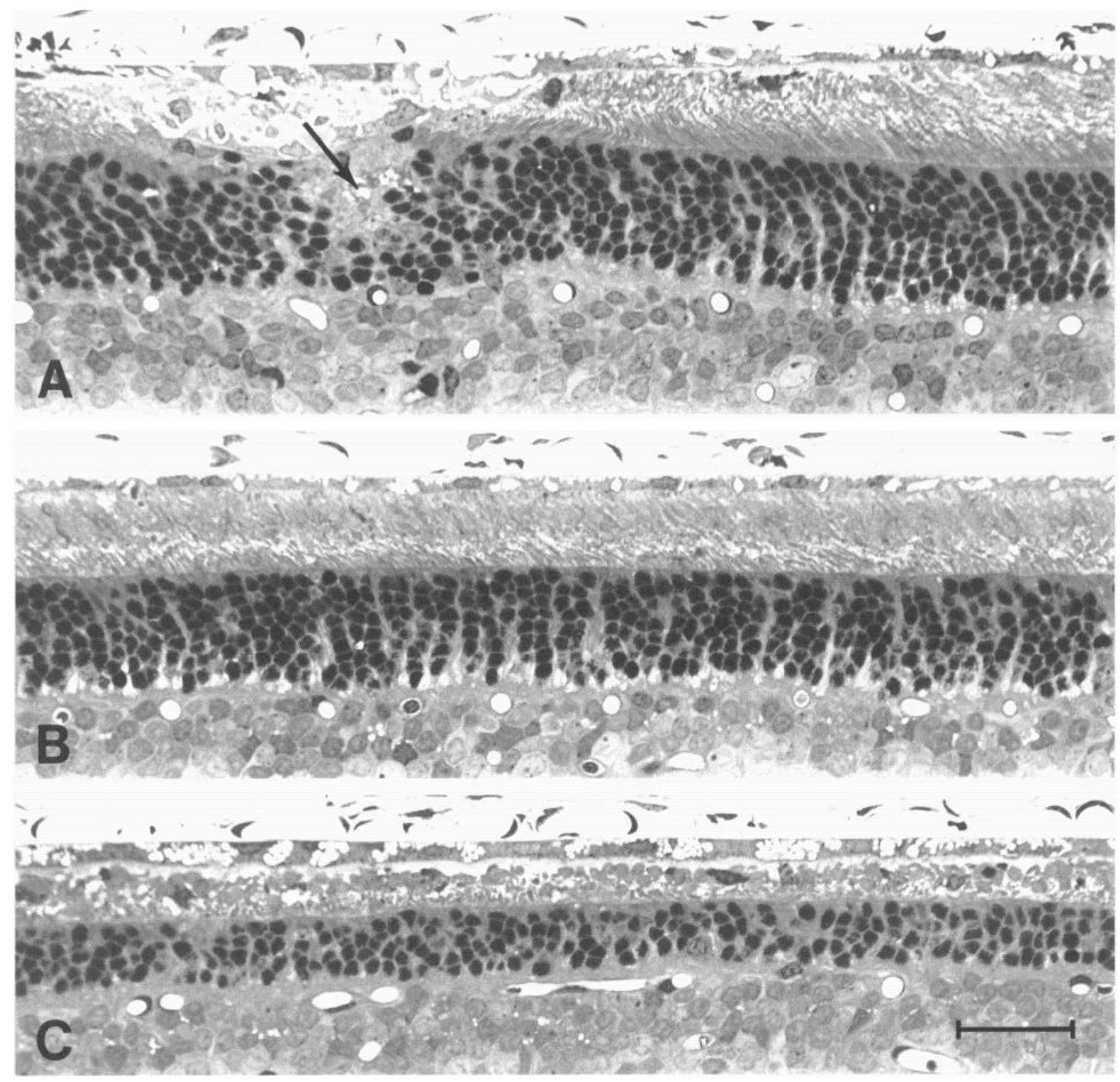

Figure 8. Light micrographs from a single retina in which a dry needle was inserted into the subretinal space and ONL $2 \mathrm{~d}$ before a 1 week constant light exposure. $A$, Region of the superior equatorial retina where the needle was inserted (arrow). Immediately adjacent to the site of injury, photoreceptor inner and outer segments are relatively well preserved. $B$, This region is located several hundred micrometers peripheral to the injury site in the superior hemisphere, and the retina appears as well preserved as that immediately adjacent to the injury $(A)$. $C$, Retina in the inferior retina in which no rescue has occurred. Toluidine blue stain. Scale bar, $30 \mu \mathrm{m}$.

(Noell, 1980; Anderson et al., 1984; Wiegand et al., 1984; Handelman and Dratz, 1986). Cell death in RCS rats results from an as yet undefined genetic defect in the RPE (Mullen and LaVail, 1976) that disrupts one or more photoreceptor-RPE cell interactions vital to the photoreceptor (LaVail, 1981b). While the steps in the etiology of cell death appear to differ in these two forms of retinal degeneration, there may be mechanisms in common, beginning at some unknown stage in the injury pathway. Since bFGF rescues photoreceptors in both forms of retinal degeneration, it is tempting to infer that it acts as a survivalpromoting factor by influencing this shared pathway. This may be further generalized to its rescue effect in other neuronal systems and with different pathological processes (e.g., axotomy, ontogenetic cell death, etc.). Thus, the peptide may act in an essential pathway that protects or repairs, via an as yet undefined molecular mechanism, that is common to many neuronal types and cytopathological processes (e.g., Mattson et al., 1989).

It is possible that bFGF acts in the normal retina as a survival or neurotrophic factor. We previously suggested that the RCS rat may, in fact, have a specific defect in the production, presence, or responsiveness to bFGF (Faktorovich et al., 1990), and this is suggested by the recent finding of a reduced number of bFGF receptors on the dystrophic RPE cell surface (Hicks et al., 1991). It is possible that constant light may also induce such a defect in bFGF. In both cases, then, the rescue effect would occur by injected bFGF acting to promote the survival of cells that are degenerating because of the loss of its normal activity.

The superior central retina showed the greatest relative rescue 

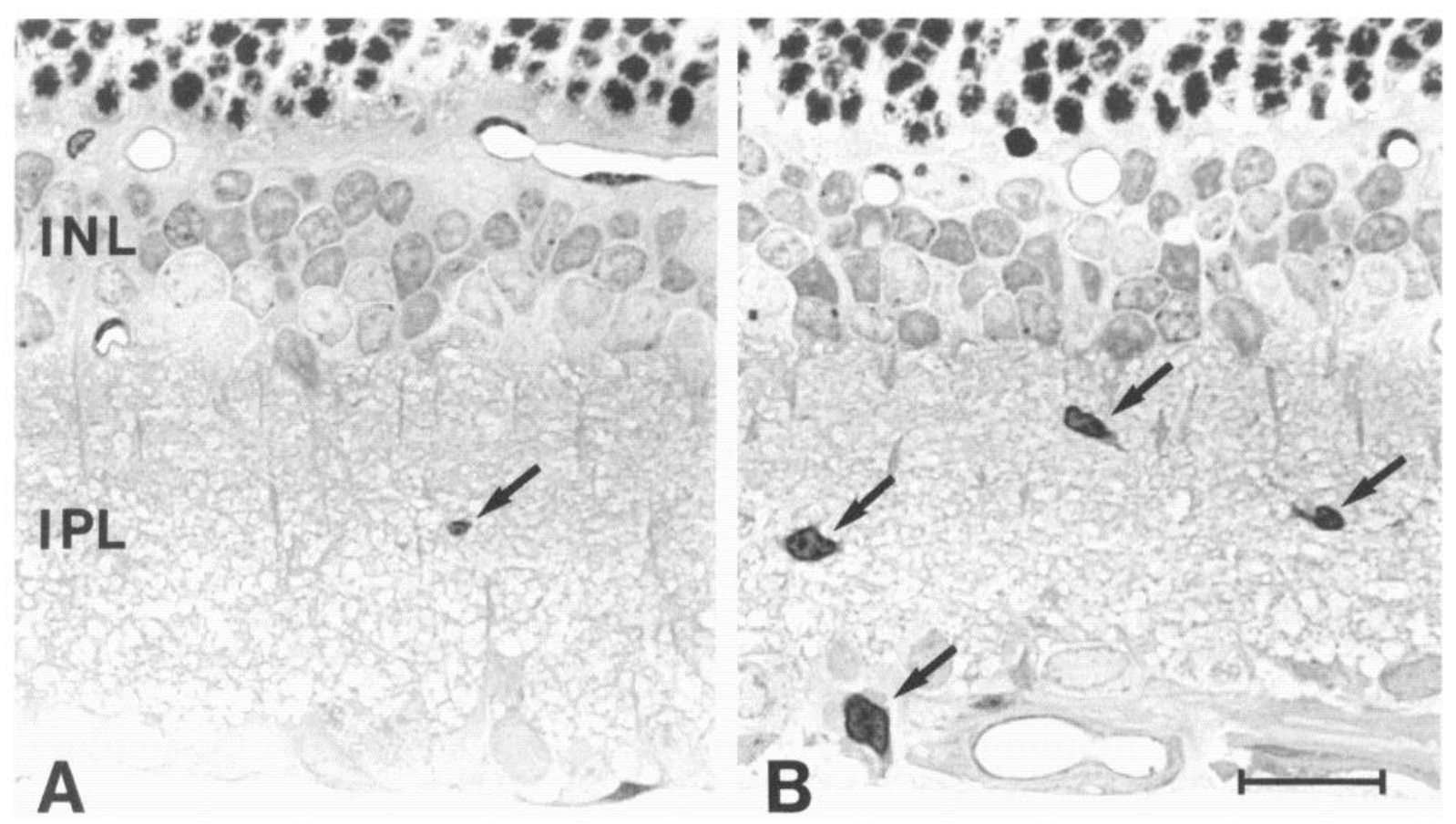

Figure 9. Light micrographs illustrating presumptive macrophages (arrows) in the inner retina of a normal, uninjected eye $(A)$ and an eye intravitreally injected with bFGF $2 \mathrm{~d}$ before a 1 week constant light exposure $(B)$. A greater number was typically seen in the bFGF-injected eyes (see Fig. 10). INL, inner nuclear layer. Toluidine blue stain. Scale bar, $20 \mu \mathrm{m}$.

by bFGF, and this is also the region most sensitive to the damaging effects of light (Noell, 1979; Rapp and Williams, 1980; LaVail et al., 1987c). This may have occurred because bFGF was injected into the superior hemisphere of the eye, providing a higher concentration there. Alternatively, this region may be intrinsically more susceptible to light damage (Rapp and Williams, 1980), as well as to rescue by bFGF. In addition, we cannot exclude possible bFGF interaction with a presumptive injury-induced factor produced by the intravitreal injection; however, rescue by such a factor alone was restricted to the area surrounding the needle, which was located far from the region most sensitive to constant light. Moreover, in some preliminary experiments we have found that by injecting through the cornea, bFGF produces photoreceptor rescue without apparent retinal injury (M. M. LaVail, D. Yasumura, M. T. Matthes, K. Unoki, and R. H. Steinberg, unpublished observations).

\section{Photoreceptor rescue with insertion of dry needle into the subretinal space}

The insertion of a dry needle (or PBS injection) into the subretinal space $2 \mathrm{~d}$ before a 1 week light exposure resulted in a remarkable degree of photoreceptor rescue that extended throughout much of the superior hemisphere in all eyes, and sometimes into the inferior hemisphere. Comparable experiments in the RCS rat also resulted in photoreceptor rescue (Faktorovich et al., 1990; Silverman and Hughes, 1990; Blair et al., 1991). Moreover, lesions caused by laser resulted in an enhanced physiological preservation of the retina of RCS rats, as measured electroretinographically (Behbehani et al., 1984). It should be emphasized that the extent of rescue in our light-damage experiments resulting from the insertion of a needle into the subretinal space was far greater than that produced by insertion into the vitreous (intravitreal injection), extending up to 5000-
$6500 \mu \mathrm{m}$ and $100-800 \mu \mathrm{m}$ of retinal length, respectively. This difference is presumably due to the much greater cellular damage in the case of the subretinal injection, with its very shallow trajectory and more extensive traverse through retinal (and RPE) tissue.

We suggested previously that injury-induced rescue in the RCS rat might be mediated by the release of endogenous bFGF from cells damaged by these procedures (Faktorovich et al., 1990). This was based on the finding in other systems of bFGF release from mechanically injured cells (Finklestein et al., 1988; McNeil et al., 1989), and our own finding in RCS rats that the degree of rescue generally was proportional to the degree of injury produced by the injection or needle insertion into the subretinal space (Faktorovich et al., 1990). Subsequent work has demonstrated the presumptive release of bFGF (or bFGFcontaining cellular debris) following injury in CNS tissue (Frautschy et al., 1991) and the presence of bFGF in rat RPE and neural retina (Connolly et al., 1991). The possibility exists, however, that this injury-induced photoreceptor rescue may not be due to bFGF released from RPE or other cells (see Increase in incidence of macrophages, below), but rather to some other mechanism or factor.

Remarkably, the areal distribution of the subretinal injuryinduced photoreceptor rescue was much greater in the lightdamage experiments than in RCS rats. Indeed, the area of rescue in RCS rats was restricted most often to the needle tract (Faktorovich et al., 1990; Blair et al., 1991), like that in the present intravitreal injections of PBS. One possible explanation of the difference resides in the experimental protocol, where the postinjury or postinjection interval was $7 \mathrm{~d}$ in the light damage experiments and 1-2 months for RCS rats. Injury from the subretinal needle may release some factor(s), perhaps bFGF, that initially diffuses widely but is most concentrated near the 

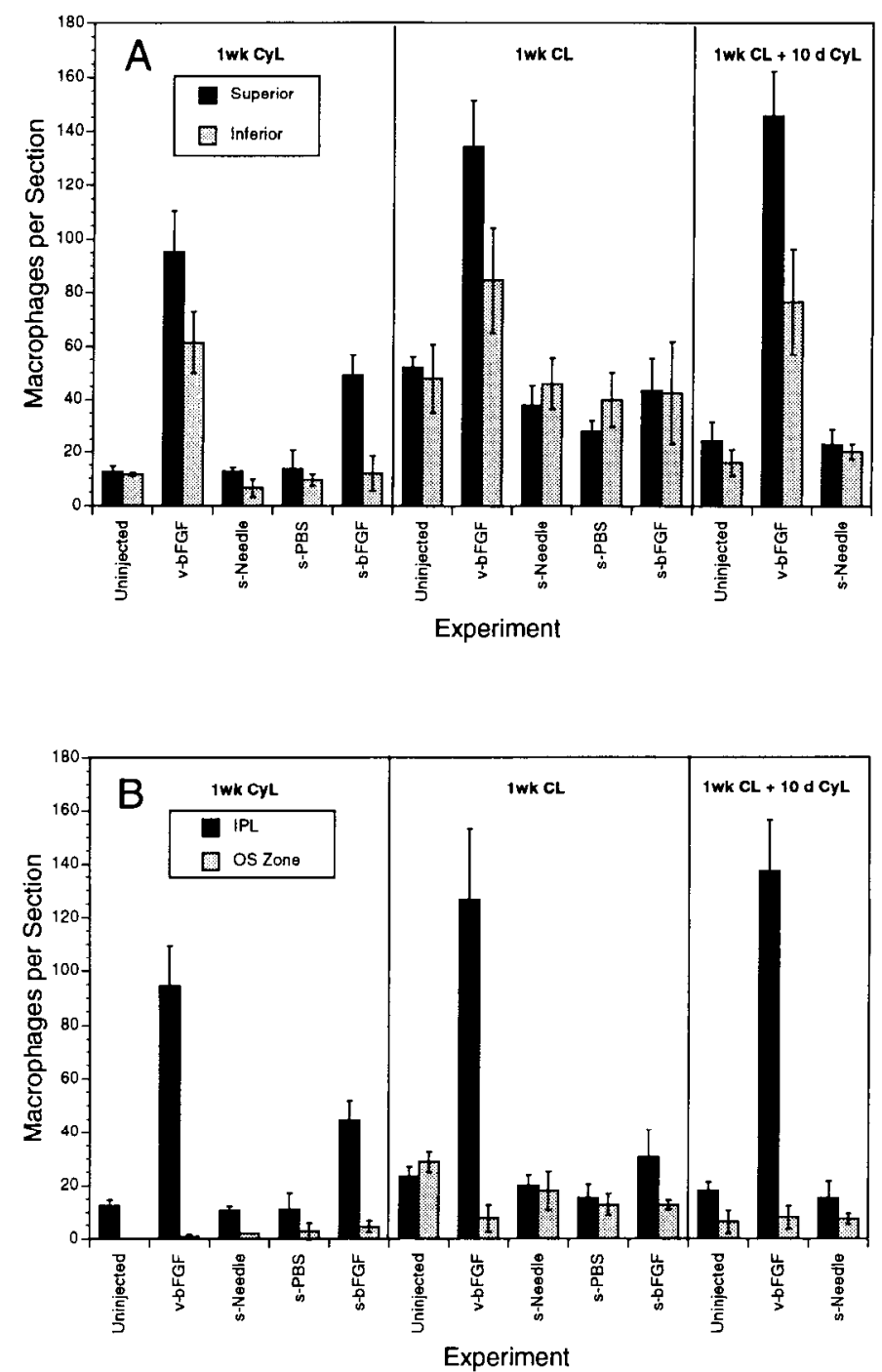

Figure 10. Counts of presumptive macrophages in retinal sections following various experimental procedures. Counts are subdivided into superior and inferior hemispheres without regard for the location in the inner retina or the outer segment zone $(A)$, or subdivided into the inner retina (IPL) and outer segment zone (OS Zone), in which case only data from the superior retina are shown, since this is the hemisphere into which the subretinal injections were done $(B)$. Values are the mean $( \pm S D)$ of counts from four or five sections, each from a different animal. $v$-, intravitreal injection; $s$-, subretinal injection.

injury site. With time, the rescue effect of the liberated factor presumably dissipates, most rapidly at the distal regions of low concentration. Preliminary light-damage observations show that the duration of the full rescue potential of intravitreally injected bFGF is only about 1 week (LaVail et al., 1991). Thus, in RCS rats, injury-induced photoreceptor rescue initially may have extended much farther out from the injury site and then contracted back to the region where the concentration of the liberated factor) was highest (i.e., the injury site).

It is possible that other, more complex explanations may underlie both the mechanisms of photoreceptor rescue following injury and the different distribution of rescue in RCS rats and in light damage. This includes the release of a factor(s) that stimulates other cells to provide a rescue factor, or the introduction of blood-derived factor(s) during the injury (Yoshida and Gage, 1991). Regardless of the mechanism, these observations make the significant point that survival-promoting fac- tors, and perhaps bFGF, are readily available to provide a protective role in the retina in case of various sorts of injury. Indeed, recent immunocytochemical studies have shown that most layers of the retina and RPE contain bFGF (Hanneken et al., 1989, Connolly et al., 1991; Ishigooka et al., 1992). The peptidc also appears to reside in the interphotoreceptor matrix that lies between the retina and the RPE (Plouët et al., 1986; Hageman et al., 1991), as does at least one other survival-promoting factor (Hewitt et al., 1990).

Injury-induced photoreceptor rescue resembles the "conditioning lesion" effect previously described in the CNS and PNS (McQuarrie et al., 1977; Nieto-Sampedro el al., 1987; PerezPolo et al., 1990). In this experimental paradigm, an initial (conditioning) lesion substantially facilitates the recovery that follows a subsequent (test) lesion, when compared to the recovery observed following only a single lesion. In sensory or motor nerve injury, for example, signs of repair such as the delay of outgrowth, its rate, as well as numbers of regenerating myelinated axons are all improved when a test lesion follows a conditioning lesion (McQuarrie, 1978; McQuarrie and Grafstein, 1981; Jenq et al., 1988). In another paradigm, prior injury to the brain (reviewed by Nieto-Sampedro et al., 1984) and extracts from injured brain (Nieto-Sampedro et al., 1984) have been shown to enhance the survival of brain tissue transplants. In addition, a time-dependent increase in the level of neuron survival-promoting factors (up to $6 \mathrm{~d}$ in pups, $16 \mathrm{~d}$ in adults) was found near the injury site (Nieto-Sampedro et al., 1982, 1983; Manthorpe et al., 1983). There is some evidence that these factors differ immunologically from NGF (Manthorpe et al., 1983), are not derived from blood or serum (Neito-Sampedro and Cotman, 1985), and may act, at least in part, by enhancing antioxidants (Jackson et al., 1990). Injury-induced photoreceptor rescue is produced by perturbing the integrity of the outer retina with a needle that breaks the blood-retinal barrier and may indeed represent an example of the conditioning lesion effect. We have not yet shown, however, that the rescue effect requires a delay of some days (or even weeks) to condition the site. Our effect also is distinct from other conditioning lesion paradigms in that it involves delaying or preventing neuronal death in two conditions where the "test lesion" is actually a degenerative process and not a trauma-induced lesion.

\section{Increase in incidence of macrophages}

Intravitreal and subretinal injection of bFGF markedly increased the incidence of presumptive macrophages, even in rats maintained in cyclic light. The mechanism of this increase is unclear. bFGF may elicit an influx of cells, or it may stimulate resident or invading cells to proliferate. Macrophages have been shown by tritiated thymidine incorporation to proliferate in retinal degenerations (Gloor, 1974; LaVail, 1979). In the present experiments, only two or three cell divisions would have been needed for the increased number observed during the $9 \mathrm{~d}$ following bFGF injection in the rats kept in cyclic light, and onc cell division in the rats exposed to constant light.

In our previous study on photoreceptor rescue by bFGF in RCS rats (Faktorovich et al., 1990), we also found an increased incidence of presumptive macrophages in the inner retina. This raised the question of the role of these cells in the rescue process, since they contain and release bFGF (Baird et al., 1985b; Gospodarowicz, 1990) and other growth factors and are vital elements in wound healing. Our evidence from light damage suggests, however, that macrophages may not be key players in the 
rescue process. While macrophage numbers increased with vitreal bFGF, with subretinal bFGF their numbers were not greater than with constant light alone, even in the superior hemisphere where photoreceptor rescue was greatest (Fig. 10A). An increased macrophage incidence was not associated with injuryinduced rescue, since there was no increase in their number in subretinal needle or PBS-injected eyes (Fig. 10). We cannot exclude a role for macrophages in either of the rescue processes, however, because they contain various growth factors (Yoshida and Gage, 1991), and their incidence is greater in constant light than in cyclic light, so they could interact with exogenous bFGF or injury-induced factors (Yoshida and Gage, 1991) to assist in the rescue process either with or without an increased incidence. It should be noted, however, that macrophages appear incapable of rescuing photoreceptors in the RCS rat ( $\mathrm{Li}$ et al., 1991). Further, more direct, experiments will be necessary to determine if macrophages play any role in rescue by bFGF or injury.

The macrophage counts also provide some information about the possible nature of the injury-induced rescue. We found that intravitreal bFGF produced an increase in macrophages while the injury-related procedures did not, yet both produced photoreceptor rescue. This could be taken as negative evidence for a significant role for bFGF in injury-induced rescue. There are, however, a number of alternative explanations for this finding. bFGF, for instance, may have been released from injured cells at a concentration sufficient to produce rescue but insufficient to increase the number of macrophages, since these mechanisms may have different thresholds. Another possibility is that an inhibitory factor is released during injury that counteracts the stimulatory effect of bFGF on macrophage numbers. In conclusion, a putative role for bFGF in injury-related rescue remains to be determined.

\section{Light damage as a model for studying the mechanisms of bFGF action}

As noted in the introductory remarks, we sought a better-controlled model than the RCS rat for exploring the cellular site(s), kinetics, and molecular mechanisms of the normal function of bFGF in the retina and the survival-promoting activity of the growth factor in vivo. Light damage in the albino rat retina offers many attributes for such studies. The "lesion" is produced noninvasively; the growth factor is administered in a relatively noninvasive manner and at a relatively controlled concentration within the eye; the intensity and duration of the light can be varied to regulate the rate and degree of cell degeneration; the period of cell degeneration can be relatively short, from several days to 1-2 weeks; the experiments can be carried out on commercially available rats; and the animals can be used at almost any age (with age-matched controls), unlike the age-dependent experiments that must be done with an inherited neuronal degeneration such as that in the RCS rat. Thus, light damage in the retina offers advantages over many other in vivo systems to study the survival-promoting activity of bFGF.

\section{References}

Anderson KJ, Dam D, Lee S, Cotman CW (1988) Basic fibroblast growth factor prevents death of lesioned cholinergic neurons in vivo. Nature 332:360-361.

Anderson RE, Rapp LM, Wiegand RD (1984) Lipid peroxidation and retinal degeneration. Curr Eye Res 3:223-227.

Baird A, Esch F, Gospodarowicz D, Guillemin R (1985a) Retina- and eye-derived endothelial cell growth factors: partial molecular char- acterization and identity with acidic and basic fibroblast growth factors. Biochemistry 24:7855-7860.

Baird A, Mormède P, Böhlen P (1985b) Immunoreactive fibroblast growth factor in cclls of pcritoncal cxudate suggests its identity with macrophage-derived growth factor. Biochem Biophys Res Commun 126:358-364.

Battelle B-A, LaVail MM (1978) Rhodopsin content and rod outer segment length in albino rat eyes: modification by dark adaptation. Exp Eye Res 26:487-497.

Behbehani MM, Bowyer DW, Ruffolo JJ, Kranias G (1984) Preservation of retinal function in the RCS rat by laser treatment. Retina 4:257-263.

Birch D, Jacobs GH (1977) Effects of constant illumination on vision in the albino rat. Physiol Behav 19:255-259.

Blair JR, Gaur V, Laedtke TW, Li L, Liu Y, Sheedlo H, Yamaguchi K, Yamaguchi K, Turner JE (1991) In oculo transplantation studies involving the neural retina and its pigment epithelium. In: Progress in retinal research, Vol 10 (Osborne $\mathrm{N}$, Chader $\mathrm{G}$, eds), pp 69-88. Oxford: Pergamon.

Connolly SE, Hjelmeland LM, LaVail MM (1991) Localization of bFGF in developing retinas of normal and RCS rats. Invest Ophthalmol Vis Sci [Suppl] 32:754.

Courty J, Loret C, Moenner M, Chevallier B, Lagente O, Courtois Y, Barritault D (1985) Bovine retina contains three growth factor activities with different affinity to heparin: eye derived growth factor $\mathbf{I}$, II, III. Biochimie 67:265-269.

D'Amore PA, Klagsbrun M (1984) Endothelial cell mitogens derived from retina and hypothalamus: biochemical and biological similarities. J Cell Biol 99:1545-1549.

Dreyer D, Langrange A, Grothe C, Unsicker K (1989) Basic fibroblast growth factor prevents ontogenetic neuron death in vivo. Neurosci Lett 99:35-38.

Engele J, Bohn MC (1991) The neurotrophic effects of fibroblast growth factors on dopaminergic neurons in vitro are mediated by mesencephalic glia. J Neurosci 1 1:3070-3078.

Essner E, Gorrin G (1979) An electron microscopic study of macrophages in rats with inherited retinal dystrophy. Invest Ophthalmol Vis Sci 18:11-25.

Faktorovich EG, Steinberg RH, Yasumura D, Matthes MT, LaVail MM (1990) Photoreceptor degeneration in inherited retinal dystrophy delayed by basic fibroblast growth factor. Nature 347:83-86.

Faktorovich EG, Steinberg RH, Yasumura D, Matthes MT, LaVail MM (1991) Photoreceptor rescue in retinal degenerations by basic fibroblast growth factor. In: Retinal degenerations (Anderson RE, Hollyfield JG, LaVail MM, eds), pp 101-108. Boca Raton, FL: CRC.

Finklestein SP, Apostolides PJ, Caday CG, Prosser J, Philips MF, Klagsbrun M (1988) Increased basic fibroblast growth factor (bFGF) immunoreactivity at the site of focal brain wounds. Brain Res 460:253259.

Frautschy SA, Walicke PA, Baird A (1991) Localization of basic fibroblast growth factor and its mRNA after CNS injury. Brain Res 553:291-299.

Gloor BP (1974) On the question of the origin of macrophages in the retina and the vitreous following photocoagulation (autoradiographic investigations by means of ${ }^{3} \mathrm{H}$-thymidine). Albrecht Von Graefes Arch Klin Exp Ophthalmol 190:183-194.

Gospodarowicz D (1990) Fibroblast growth factor and its involvement in developmental processes. In: Current topics in developmental biology (Hamilton MN, ed), pp 57-93. San Diego: Academic.

Gouras P, Lopez R, Kjeldbye H, Sullivan B, Brittis M (1989) Transplantation of retinal epithelium prevents photoreceptor degeneration in the RCS rat. Prog Clin Biol Res 314:659-671.

Grignolo A, Orzalesi N, Castellazzo R, Vittone P (1969) Retinal damage by visible light in albino rats. Ophthalmologica 157:43-59.

Grothe C, Otto D, Unsicker K (1989) Basic fibroblast growth factor promotes in vitro survival and cholinergic development of rat septal neurons: comparison with the effects of nerve growth factor. Neuroscience 31:649-661.

Hageman GS, Kirchoff-Rempe MA, Lewis GP, Fisher SK, Anderson DH (1991) Sequestration of basic fibroblast growth factor in the primate retinal interphotoreceptor matrix. Proc Natl Acad Sci USA 88:6706-6710.

Handelman GJ, Dratz EA (1986) The role of antioxidants in the retina and retinal pigment epithelium and the nature of prooxidant-induced damage. Adv Free Radical Biol Med 2:1-89. 
Hanneken A, Lutty GA, McLeod DS, Robey F, Harvey AK, Hjelmeland LM (1989) Localization of basic fibroblast growth factor to the developing capillaries of the bovine retina. J Cell Physiol 138:115120.

Hatten ME, Lynch M, Rydel RE, Sanchez J, Joseph-Silverstein J, Moscatelli D, Rifkin DB (1988) In vitro neurite extension by granule neurons is dependent upon astroglial-derived fibroblast growth factor. Dev Biol 125:280-289.

Hess HH, Newsome DA, Knapka JJ, Bieri JG (1981) Effects of sunflower seed supplements on reproduction and growth of RCS rats with hereditary retinal dystrophy. Lab Anim Sci 31:482-488.

Hewitt AT, Lindsey JD, Carbott D, Adler R (1990) Photoreceptor survival-promoting activity in interphotoreceptor matrix preparations: characterization and partial purification. Exp Eye Res 50:79_ 88

Hicks D, Bugra K, Faucheux B, Jeanny J-C, Laurent M, Malecaze F, Mascarelli F, Raulais D, Cohen Y, Courtois Y (1991) Fibroblast growth factors in the retina. In: Progress in retinal research, Vol 11 (Osborne N, Chader G, eds), pp 333-374. Oxford: Pergamon.

Ishigooka H, Aotaki-Keen A, Hjclmeland LM (1992) Subcellular localization of bFGF in human retinal pigment epithelium in vitro. Exp Eye Res, in press.

Jackson GR, Werrbach-Perez K, Perez-Polo JR (1990) Role of nerve growth factor in oxidant-antioxidant balance and neuronal injury. II. A conditioning lesion paradigm. J Neurosci Res 25:369-374.

Jenq C-B, Jenq LL, Bear HM, Coggeshall RE (1988) Conditioning lesions of peripheral nerves change regenerated axon numbers. Brain Res 457:63-69.

Kaitz M, Auerbach E (1980) Light damage in dystrophic and normal rats. In: The effects of constant light on visual processes (Williams TP, Baker BN, eds), pp 179-193. New York: Plenum.

Kuwabara T (1970) Retinal recovery from exposure to light. Am J Ophthalmol 70:187-198.

Kuwabara T, Gorn RA (1968) Retinal damage by visible light. Arch Ophthalmol 79:69-78.

Lanum J (1978) The damaging effects of light on the retina. Empirical findings, theoretical and practical implications. Surv Ophthalmol 22: 221-249.

LaVail MM (1979) The retinal pigment epithelium in mice and rats with inherited retinal degeneration. In: The retinal pigment epithelium (Zinn KM, Marmor MF, eds), pp 357-380. Cambridge, MA: Harvard IJP.

LaVail MM (1980) Eye pigmentation and constant light damage in the rat retina. In: The effects of constant light on visual processes (Williams TP, Baker B, eds), pp 357-387. New York: Plenum.

LaVail MM (1981a) Photoreceptor characteristics in congenic strains of RCS rats. Invest Ophthalmol Vis Sci 20:671-675.

LaVail MM (1981b) Analysis of neurological mutants with inherited retinal degeneration. Invest Ophthalmol Vis Sci 21:638-657.

LaVail MM, Battelle BA (1975) Influence of eye pigmentation and light deprivation on inherited retinal dystrophy in the rat. Exp Eye Res 21:167-192.

LaVail MM, Sidman RL, O'Neil DA (1972) Photoreceptor-pigment epithelial cell relationships in rats with inherited retinal degeneration. Radioautographic and electron microscope evidence for a dual source of extra lamellar material. J Cell Biol 53:185-209.

LaVail MM, Gorrin GM, Repaci MA (1987a) Strain differences in sensitivity to light-induced photoreceptor degeneration in albino mice. Curr Eye Res 6:826-834.

LaVail MM, Gorrin GM, Repaci MA, Thomas LA, Ginsberg HM (1987b) Genetic regulation of light damage to photoreceptors. Invest Ophthalmol Vis Sci 28:1043-1048.

LaVail MM, Gorrin GM, Repaci MA, Yasumura D (1987c) Lightinduced retinal degeneration in albino mice and rats: strain and species differences. In: Degenerative retinal disorders: clinical and laboratory investigations (Hollyfield JG, Anderson RE, LaVail MM, eds), pp 439-454. New York: Liss.

LaVail MM, Sidman RL, Gerhardt CO (1975) Congenic strains of RCS rats with inherited retinal dystrophy. J Hered 66:242-244.

LaVail MM, Faktorovich EG, Matthes MT, Yasumura D, Hepler JM Pearson KL, Steinberg RH (1991) bFGF protects photoreceptor cells from light damage in the rat. Invest Ophthalmol Vis Sci [Suppl] 32: 1097.

Li L, Turner JE (1988a) Transplantation of retinal pigment epithelial cells to immature and adult rat hosts: short- and long-term survival characteristics. Exp Eye Res 47:771-785
Li L, Turner JE (1988b) Inherited retinal dystrophy in the RCS rat: prevention of photoreceptor degeneration by pigment epithelial cell transplantation. Exp Eye Res 47:911-917.

Li L, Sheedlo HJ, Gaur V, Turner JE (1991) Effects of macrophage and retinal pigment epithelial cell transplants on photoreceptor cell rescue in RCS rats. Curr Eye Res. 10:947-958.

Lopez R, Gouras P, Kjeldbye H, Sullivan B, Reppucci V, Britis M Wapner F, Goluboff E (1989) Transplanted retinal pigment epithelium modifies the retinal degeneration in the $\mathrm{RCS}$ rat. Invest Ophthalmol Vis Sci 30:586-588.

Manthorpe M, Nieto-Sampedro M, Skaper SD, Lewis ER, Barbin G Longo FM, Cotman CW, Varon S (1983) Neuronotrophic activity in brain wounds of the developing rat. Correlation with implant survival in the wound cavity. Brain Res 267:47-56.

Mascarelli F, Raulais D, Counis MF, Courtois Y (1987) Characterization of acidic and basic fibroblast growth factors in brain, retina and vitreous chick embryo. Biochem Biophys Res Commun 146:478486.

Mattson MP, Murrain M, Guthrie PB, Kater SB (1989) Fibroblast growth factor and glutamate: opposing roles in the generation and degeneration of hippocampal neuroarchitecture. J Neurosci 9:37283740 .

McKechnie NM, Foulds WS (1980) Recovery of the rabbit retina after light damage. Albrecht Von Graefes Arch Klin Exp Ophthalmol 212: 271-283.

McNeil PL, Muthukrishnan L, Warder E, D'Amore PA (1989) Growth factors are released by mechanically wounded endothelial cells. J Cell Biol 109:811-822.

McQuarrie IG (1978) The effect of a conditioning lesion on the regeneration of motor axons. Brain Res 152:597-602.

McQuarrie IG, Grafstein B (1981) Effect of a conditioning lesion on optic nerve regeneration in goldfish. Brain Res 216:253-264.

McQuarrie IG, Grafstein B, Gershon MD (1977) Axonal regeneration in the rat sciatic nerve: effect of a conditioning lesion and of dbcAMP. Brain Res 132:443-453.

Michon JJ, Li ZL, Shioura N, Anderson RJ, Tso MO (1991) A comparative study of methods of photoreceptor morphometry. Invest Ophthalmol Vis Sci 32:280-284.

Mullen RJ, LaVail MM (1976) Inherited retinal dystrophy: primary defect in pigment epithelium determined with experimental rat chimeras. Science 192:799-801.

Neito-Samepedro M, Cotman CW (1985) Growth factor induction and temporal order in central nervous system repair. In: Synaptic plasticity (Cotman CW, ed), pp 407-455. New York: Guilford.

Nieto-Sampedro M, Lewis ER, Cotman CW (1982) Brain injury causes a time-dependent increase in neuronotrophic activity at the lesion site. Science 217:860-861.

Nicto-Sampedro M, Manthrope M, Barbin G, Varon S, Cotman CW (1983) Injury-induced neuronotrophic activity in adult rat brain: correlation with survival of delayed implants in the wound cavity. J Neurosci 3:2219-2229.

Nieto-Sampedro M, Whittemore SR, Needels DL, Larson J, Cotman CW (1984) The survival of brain transplants is enhanced by extracts from injured brain. Proc Natl Acad Sci USA 81:6250-6254

Nieto-Sampedro M, Kesslak JP, Gibbs R, Cotman CW (1987) Effects of conditioning lesions on transplant survival, connectivity, and function. Ann NY Acad Sci 495:108-119.

Noell WK (1979) Effects of environmental lighting and dietary vitamin A on the vulnerability of the retina to light damage. Photochem Photobiol 29:717-723.

Noell WK (1980) Possible mechanisms of photoreceptor damage by light in mammalian eyes. Vision Res 20:1163-1171.

Noell WK, Walker VS, Kang BS, Berman S (1966) Retinal damage by light in rats. Invest Ophthalmol 5:450-473.

Noji S, Matsuo T, Koyama E, Yamaai T, Nohno T, Matsuo N, Taniguchi S (1990) Expression pattern of acidic and basic fibroblast growth factor genes in adult rat eyes. Biochem Biophys Res Commun 168:343-349.

O'Steen WK, Lytle RB (1971) Early cellular disruption and phagocytosis in photically-induced retinal degeneration. Am J Anat 130: 227-234.

O'Steen WK, Karcioglu ZA (1974) Phagocytosis in the light-damaged albino rat eye: light and electron microscopic study. Am J Anat 139: 503-518.

O'Steen WK, Shear CR, Anderson KV (1972) Retinal damage after 
prolonged exposure to visible light. A light and electron microscopic study. Am J Anat 134:5-22.

Otto D, Frotscher M, Unsicker K (1989) Basic fibroblast growth factor and nerve growth factor administered in gel foam rescue medial septal neurons after fimbria fornix transection. J Neurosci Res 22:83-91.

Park CM, Hollenberg MJ (1989) Basic fibroblast growth factor induces retinal regeneration in vivo. Dev Biol 134:201-205.

Perez-Polo JR, Foreman PJ, Jackson GR, Shan D, Taglialatela G, Thorpe I.W, Werrbach-Perez. K (1990) Nerve growth factor and neuronal cell death. In: Molecular neurobiology (Bazan NG, ed), pp 57-90. Clifton, NJ: Humana.

Plouët J (1988) Molecular interaction of fibroblast growth factor, lightactivated rhodopsin and s-antigen. In: Molecular biology of the eye: genes, vision and ocular disease (Piatigorsky J, Toshimichi S, Zelenka PS, eds), pp 83-92. New York: Liss.

Plouët J, Mascarelli F, Lagente O, Dorey C, Lorans G, Faure JP, Courtois $Y$ (1986) Eye derived growth factor: a component of rod outer segment implicated in phototransduction. In: Retinal signal systems, degenerations and transplants (Agardh E, Ehinger B, eds), pp 311320. New York: Elsevier.

Plouët J, Mascarelli F, Loret MD, Faure JP, Courtois Y (1988) Regulation of eye derived growth factor binding to membranes by light, ATP or GTP in photoreceptor outer segments. EMBO J 7:373-376.

Rapp LM, Williams TP (1980) A parametric study of retinal light damage in albino and pigmented rats. In: The effects of constant light on visual processes (Williams TP, Baker BN, cds), pp 135-159. Ncw York: Plenum.

Sanyal S (1972) Changes of lysosomal enzymes during hereditary degeneration and histogenesis of retina in mice. II. Localization of $\mathrm{N}$ acetyl- $\beta$-glucosaminidase in macrophages. Histochemie 29:28-36.

Sanyal S, De Ruiter A, Dees C (1984) Light dependent accumulation of macrophages at the photoreceptor-pigment epithelial interface in the retina of albino mice. Experientia 40:852-854.

Schweigerer L, Malerstein B, Neufeld G, Gospodarowicz D (1987) Basic fibroblast growth factor is synthesized in cultured retinal pigment epithelial cells. Biochem Biophys Res Commun 143:934-940.
Shear CR, O'Steen WK, Anderson KV (1973) Effects of short-term low intensity light on the albino rat retina. An electron microscopic study (1). Am J Anat 138:127-132.

Sievers J, Hausmann B, Unsicker K, Berry M (1987) Fibroblast growth factors promote the survival of adult rat retinal ganglion cells after transection of the optic nerve. Neurosci Lett 76:157-162.

Silverman MS, Hughes SE (1990) Photoreceptor rescue in the RCS rat without pigment epithelium transplantation. Curr Eye Res 9:183191

Steinberg RH, Faktorovich EG, Yasumura D, Matthes MT, LaVail MM (1991) bFGF and photoreceptor regeneration. In: CIBA symposium on growth and development, CIBA Foundation Symposium 160 (Bock GR, Whelan J, eds), pp 219-232. New York: Wiley.

Sternfeld MD, Robertson JE, Shipley GD, Tsai J, Rosenbaum JT (1989) Cultured human retinal pigment epithelial cells express basic fibroblast growth factor and its receptor. Curr Eye Res 8:1029-1037.

Unsicker K, Reichert-Preibsch H, Schmidt R, Pettman B, Labourdette $\mathrm{G}$, Sensenbrenner M (1987) Astroglial and fibroblast growth factors have neurotrophic functions for cultured peripheral and central nervous system neurons. Proc Natl Acad Sci USA 84:5459-5463.

Walicke PA, Baird A (1988) Neurotrophic effects of basic and acidic fibroblast growth factors are not mediated through glial cells. Brain Res 468:71-79.

Wiegand RD, Jose JG, Rapp LM, Anderson RE (1984) Free radicals and damage to ocular tissues. In: Free radicals in molecular biology, aging, and discase (Armstrong D, Sohal RS, Cutler RG, Slater TF, eds), pp 317-353. New York: Raven.

Williams TP, Howell WL (1983) Action spectrum of retinal lightdamage in albino rats. Invest Ophthalmol Vis Sci 24:285-287.

Wyse JPH (1980) Renewal of rod outer segments following lightinduced damage of the retina. Can J Ophthalmol 15:15-19.

Yoshida K, Gage FH (1991) Fibroblast growth factors stimulate nerve growth factor synthesis and secretion by astrocytes. Brain Res 538: $118-126$.

Young RW (1967) The renewal of photoreceptor cell outer segments. J Cell Biol 33:61-72. 